\title{
Subcutaneous Mycosis in Hospitals: Study of 3 Cases at The National University Hospital Centre Hubert Koutoukou Maga in Cotonou (Benin)
}

\author{
Akpadjan $\mathrm{F}^{1^{*}}$, Sissinto Savi de Tov $^{2}$, Azon Kouanou ${ }^{3}$, Houeho $\mathrm{F}^{4}$, Houngbo ${ }^{1}$, Degboe $\mathrm{B}^{1}$, Seidou $\mathrm{F}^{5}$, \\ Atadokpede $\mathbf{F}^{1}$ \\ ${ }^{1}$ Dermatology-Venerology, Faculty of Health Sciences, Cotonou / UAC, Benin \\ ${ }^{2}$ Parasitology-Mycology Laboratory, Faculty of Health Sciences, Cotonou / UAC, Benin \\ ${ }^{3}$ Internal Medicine, Faculty of Health Sciences, Cotonou / UAC, Benin \\ ${ }^{4}$ UFR-Pharmacy, Faculty of Health Sciences, Cotonou / UAC, Benin \\ ${ }^{5}$ Pathological Anatomy Laboratory, Faculty of Health Sciences, Cotonou / UAC, Benin
}

\begin{abstract}
Received: August 11 ${ }^{\text {th }}, 2021$; Accepted: August 25 ${ }^{\text {th }}, 2021$; Published: September 27 ${ }^{\text {th }}, 2021$
*Corresponding author: AKPADJAN Fabrice, Dermatology-Venerology, Faculty of Health Sciences, University of Abomey-Calavi, Cotonou (Benin); Tel. No : (+229) 970744 09; E-mail: barfice@yahoo.fr
\end{abstract}

\section{Abstract}

Introduction: Deep subcutaneous mycosis results from the involvement of subcutaneous tissue by microscopic fungi. Few studies have been conducted on these diseases in Benin.

Patients and methods: This was a retrospective descriptive study that included all cases of subcutaneous mycosis recorded in the Dermatology-Venerology Department of the CNHU-HKM from 2009 to 2020.

Results: 3 cases of deep subcutaneous mycosis were recorded in 12 years, including two cases of

basidiobolomycosis and one case of fungal mycetoma. The cases of basidiobolomycosis were observed in two girls aged 7 and 8 years whose lesions were located on the right buttock, in the form of indurated placards, adherent to the superficial plane, measuring respectively $10 \mathrm{~cm}$ by $5 \mathrm{~cm}$ and $14 \mathrm{~cm}$ by $7 \mathrm{~cm}$. Mycological examination of the biopsy specimens isolated Basidiobolus ranarum. The only case of fungal mycetoma was observed in a 39-year-old man, in the form of a nodular placard measuring $14 \mathrm{~cm}$ by $12 \mathrm{~cm}$, polyfistulised, inflammatory and squamous-crusty with an irregular border that had been evolving for 15 years. Mycological examination of the pus revealed the presence of black grains and the identification of Madurella mycetomatis. Treatment with Ketoconazole was initiated in all three patients but the evolution could not be appreciated.

Conclusion : Subcutaneous mycosis is rare in Cotonou, but probably underestimated.

Keywords: Subcutaneous Mycosis; Mycetoma;
Basidiobolomycosis; Benin

\section{Introduction}

Deep mycosis is becoming an increasingly important infectious disease in all countries of the world [1]. They are subdivided into cosmopolitan deep mycosis and tropical deep mycosis with disseminated and subcutaneous forms. Subcutaneous mycosis is caused by microscopic fungi affecting the subcutaneous tissue. They are represented by chromomycosis, phaeohyphomycosis, fungal mycetoma and zygomycosis. The latter include mucormycosis and entomophtoromycosis represented by conidiobolomycosis and basidiolobomycosis [2]. They are rare, especially in urban areas. Few studies have been conducted on these fungi in Benin. The aim of the present study was to list the cases of deep mycosis followed in the Dermatology and Venereology Department of the largest hospital in Benin and to describe their epidemiological, clinical, paraclinical, therapeutic and evolutionary characteristics.

\section{Patients and Methods}

This was a retrospective study with a descriptive aim which included the files of all patients received for deep mycosis in the Dermatology-Venerology Department of the CNHU-HKM from 2009 to 2020 (12 years). First, we consulted the consultation registers of the years concerned. Then we identified patients with a diagnosis of subcutaneous mycosis. Finally, the files of these patients were consulted. Socio-demographic, clinical, paraclinical, therapeutic and evolutionary data were thus collected.

\section{Results}

We registered 3 cases of subcutaneous mycosis in the department, including two cases of basidiobolomycosis and one case of fungal mycetoma. The cases of basidiobolomycosis were observed in two girls aged 7 and 8 years residing in Atchoukpa and Sèmé podji (rural areas). The lesions were located on the right 
buttock +/- right thigh. Clinically the lesions were almost identical; they were normochromic +/- hyperpigmented swollen plaques, indurated, adherent to the superficial plane (figure), measuring respectively $10 \mathrm{~cm}$ by $5 \mathrm{~cm}$ and $14 \mathrm{~cm}$ by $7 \mathrm{~cm}$. One of the patients had a limp when walking. Mycological examination of the biopsy specimens isolated Basidiobolus ranarum. Treatment with Ketoconazole (150mg to $200 \mathrm{mg}$ /day) was initiated. The short-term evolution was favourable in the second patient, marked by a regression of the induration and the disappearance of the lameness after 1 month; but she was lost to view as the first one who was not seen again after the treatment.

The only case of fungal mycetoma was observed in a 39 year old man, residing in Djidjè (suburb of the economic capital), seen for a nodular placard of $14 \mathrm{~cm}$ by $12 \mathrm{~cm}$ polyfistulised, inflammatory and squamous-crusty with irregular borders evolving for 15 years. Mycological examination of the pus revealed the presence of black grains and the identification of Madurella mycetomatis.Treatment with Ketoconazole $400 \mathrm{mg} /$ day was instituted but the patient was lost to follow-up.

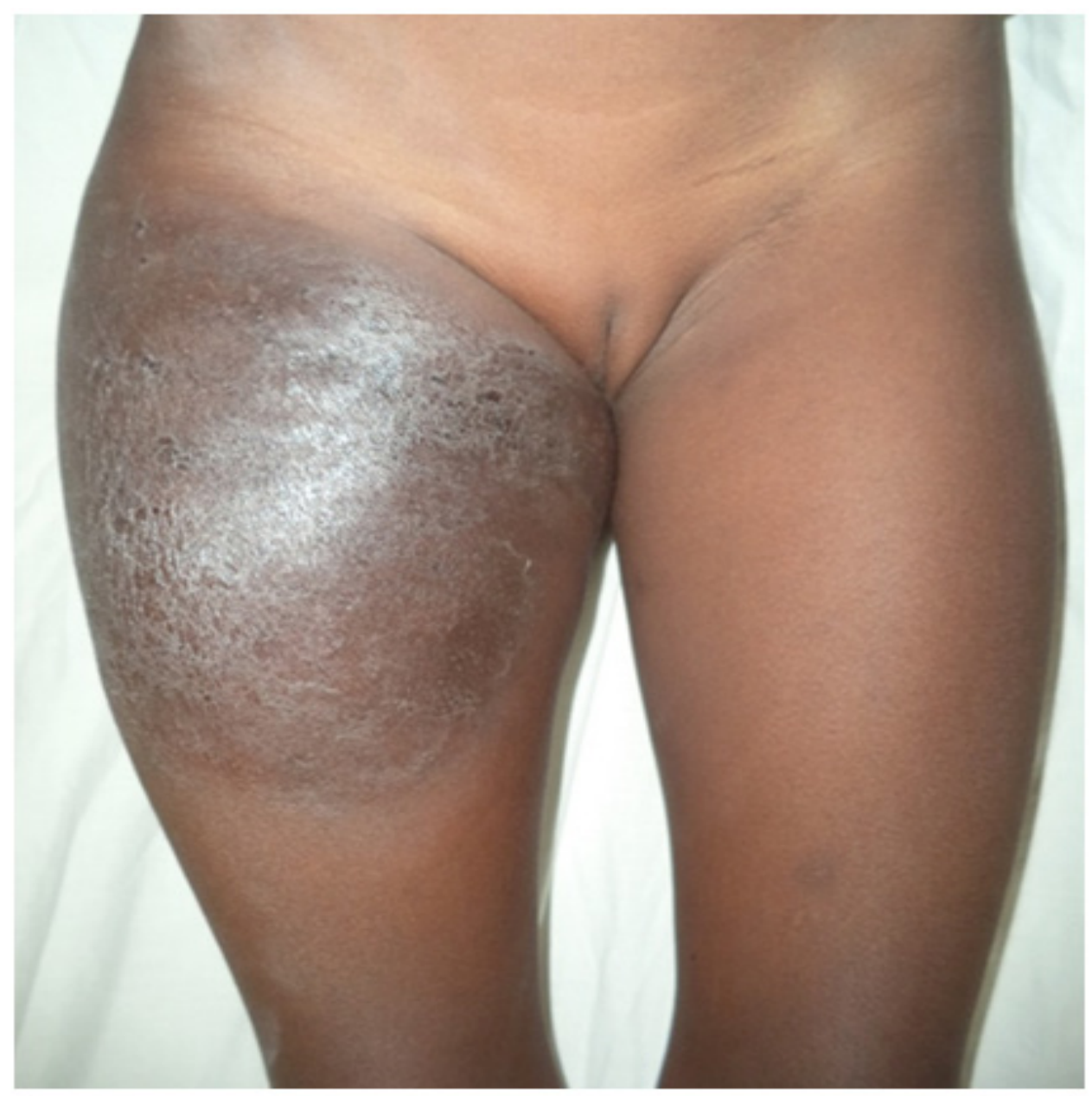

Figure : Basidiobolomycosis of the right thigh in a 7-year-old girl

\section{Discussion}

In twelve years, only three cases of subcutaneous mycosis have been recorded in the dermatology-venereology department of the most important hospital in Benin. This low prevalence confirms the rarity of these conditions in our African countries. But it is probably underestimated, as some patients living in rural areas do not always have access to the reference centre located in the country's economic capital. These patients are mostly referred to the leprosy and Buruli ulcer diagnosis and treatment centres (CDTLUB) set up in rural areas for the management of these neglected tropical dermatoses. A study conducted in 2017 in Benin by Atadokpèdé in one of these CDTLUBs and at the CNHU recorded only six cases of basidiobolomycosis over a six-year period [3].

A general review of the biomedical literature conducted in 2012 by Kombaté over a period of 40 years identified 89 articles on basidiobolomycosis with a total of 172 cases worldwide, 47 of which were in tropical Africa [4]. Our two cases of basidiobolomycosis were observed in children; the same observation has been made by most studies in Africa and worldwide. According to Kombaté [4], patients under 15 years 
of age represented $70 \%$ of the cases. The clinical presentation was comparable to the literature [4,5]. Basidiobolus ranarum was isolated from our two patients; in the study by Tchin Darré [6] the same pathogen was identified in three of the four patients who underwent mycological examination. Physicians and other primary care workers often misdiagnose this condition because of its slow progression, painlessness, lack of response to antibiotics and anti-inflammatory drugs, and lack of awareness of the disease. In a study by S Kumaravel [7], the referral diagnoses ranged from chronic abscess to tuberculosis to malignancies, including testicular tumours [7]. Indeed, basidiobolomycosis can mimic Mycobacterium ulcerans infection, or other malignancies leading frontline physicians to improper limb amputations due to diagnostic error [5,7].

The only case of fungal mycetoma observed over a period of twelve years in this study also confirms the rarity of this deep mycosis in our regions. Mycetoma is endemic in tropical and subtropical regions of the world. In Africa, it predominates in Sudan, Somalia, Mauritania, Senegal and their neighbouring countries [8]. The most common clinical presentation is a fistulous swelling of the foot, but extrapodal localisations are possible, as in our patient. Several authors have also described extrapodal localisations of mycetoma [8-10]. Madurella mycetomatis and Leptosphaeria $s p$ are the main pathogens of fungal mycetoma in Africa; our case is no exception. Therapeutically, azole derivatives are effective and well tolerated on these two subcutaneous mycosis; most studies confirm the effectiveness of Ketoconazole prescribed in our three patients [4-9]. According to Develoux [10], the combination of ketoconazole and surgery gives better results in the treatment of fungal mycetomas and allows conservative surgery while reducing the risk of recurrence. However, we were not able to evaluate the evolution of our patients under treatment because they were all lost to follow-up in the medium and long term.

\section{Discussion}

Subcutaneous mycosis are rare in Cotonou, but probably underestimated. The interest of this study is to draw the attention of health workers in general and those on the front line in particular to the existence of these deep mycosis; although rare in our African regions.

\section{References}

1. Aubry P. Mycoses profondes. 2021;1-23.

2. Ramesh V, Ramam M, Capoor MR, Sugandhan S, Dhawan J, Khanna G. Subcutaneous zygomycosis: Report of 10 cases from two institutions in North India. J Eur Acad Dermatology Venereol. 2010;24(10):12201225 .

3. Atadokpédé F, Gnossikè J, Adégbidi H, Dégboé B, Tovè Y, Adéyé A, et al. Cutaneous basidiobolomycosis: Seven cases in southern Benin. Ann Dermatol Venereol. 2017;144(4):250-4.

4. Kombaté K, Saka B, Toure A, Akakpo S, Djadou KE, Darré T, et al. Basidiobolomycosis: A review. 2012;145-52.

5. Saka B, Kombaté K, Toure A, Akakpo S, Tchangaï B, Amégbor K, et al. Probable basidiobolomycosis in a Togolese rural young successfully treated with ketoconazole. Bull la Soc Pathol Exot. 2010;103(5):293295.

6. Darré T, Saka B, Toure A, Djiwa T, Pitché P, Koura G. Basidiobolomycosis in Togo: Clinico-pathological study of a series of 12 presumed cases 11 Medical and Health Sciences 1103 Clinical Sciences. BMC Res Notes. 2018;11(1):4-7.

7. Kumaravel S, Bharath K, Rajesh NG, Singh R, Kar R. Delay and misdiagnosis of basidiobolomycosis in tropical South India: Case series and review of the literature. Paediatr Int Child Health. 2016;36(1):5257.

8. Welsh 0, Cabrera L, Carmona MC. Mycetoma. Clin Dermatol. 2007;25(2):195-202.

9. Fahal A, Mahgoub ELS, EL Hassan AM, Jacoub AO, Hassan D. Head and Neck Mycetoma: The Mycetoma Research Centre Experience. PLoS Negl Trop Dis. 2015;9(3):1-13.

10. Develoux M, Dieng MT, Kane A, Ndiaye B. Management of mycetomas in West Africa. Bull la Soc Pathol Exot. 2004;96(5):376-382. 